\title{
PERCEPCIJA UKRASNOG BILJA STUDENATA AGRONOMIJE U REKREACIJSKI SPORTSKOM CENTRU JARUN U ZAGREBU
}

\author{
PERCEPTION OF HORTICULTURAL PLANTS BY AGRONOMY \\ STUDENTS IN JARUN SPORTS AND RECREATION CENTRE \\ IN ZAGREB
}

\author{
Romana Caput-Jogunica, Lukrecija Martinis
}

\section{SAŽETAK}

U Hrvatskoj nedostaje istraživanja o učincima javnih parkova na kvalitetu života stanovnika te o doživljajima ukrasnog bilja u parkovima i sve više posjećenim sportsko rekreacijskim centrima. Glavni cilj ovog rada je analiza percepcije ukrasnog bilja studenata Agronomskog fakulteta tijekom sudjelovanja $\mathrm{u}$ aerobnim kondicijskim programima koji se provode $\mathrm{u}$ Rekreacijskom sportskom centru na Jarunu. Ostali ciljevi istraživanja usmjereni su na analizu mišljenja studenata kao korisnika prostora o percepciji ukrasnog bilja i o potrebi izrade orijentacijskih karata s ucrtanim ukrasnim biljkama uz biciklističku i rolersku stazu na Jarunu. Istraživanje je provedeno putem anonimnog upitnika dizajniranog za potrebe ovog eksperimentalnog rada. Analizom odgovora utvrđeno je da većina studenata daje prednost programima tjelesnog vježbanja u prirodi. Studenti predlažu da se posade voćne vrste, magnolija, lipa, te da se uredi grmlje duž sportskih staza. Praktični rezultat ovog rada su orijentacijske karte Rekreacijskog sportskog centra Jarun s ucrtanim drvenastim biljkama koje se nalaze uz biciklističku i rolersku stazu, a koje se mogu višestruko koristiti za potrebe nastave na Agronomskom fakultetu. Rezultati ovog istraživanja potvrdili su potrebu provedbe većeg broja istraživanja o utjecaju ukrasnog bilja u rekreacijskim parkovima na kvalitetu života posjetitelja i potrebu nastavka istraživanja vezano uz primjenu orijentacijskih mapa u praktičnom dijelu nastave.

Ključne riječi: opažanje studenata, drvenaste biljke, rekreacijski parkovi, orijentacijske karte 
Romana Caput-Jogunica i Lukrecija Martinis: Percepcija ukrasnog bilja studenata agronomije u Rekreacijski sportskom centru Jarun u Zagrebu

\begin{abstract}
In the Republic of Croatia there is a lack of studies related to analysis of impact of urban parks on inhabitants' quality of life and their perception of horticultural plants in parks and frequently visited sports recreation centres. The main aim of this paper is to determine if students of Faculty of Agriculture perceive horticultural plants during their outdoor activities provided by the Jarun Sports and Recreation Centre. The second aim is to analyse the students' observations of horticultural plants and the need to draw up orientation maps with horticultural plants alongside the bicycle and roller skating path at Jarun. The study was based on the analysis of the anonymous questionnaire designed for this experimental study. According to the analysis of the students' answers, students prefer to participate in outdoor sports activities surrounded by greenery. The majority of students has suggested planting fruit trees, magnolias and lime trees as well as arranging the shrubbery alongside the sports paths. The practical result of this paper are orientation maps of the Jarun Recreation Sports Centre with drawn ornamental woody plants alongside the bicycle and roller skating paths which can be used for multiple purposes. The results of this study confirmed the need to carry out more studies in Croatia related to the impact of horticultural plants in recreational parks on the quality of visitors' life and the need to continue to analyse the application of orientation maps in the practical part of teaching.
\end{abstract}

Keywords: students' perception, ornamental woody plants, recreational parks, orientation maps

\title{
UVOD
}

Javni parkovi i otvorene zelene površine imaju stratešku važnost za kvalitetu života. Prirodno okruženje (parkovi, šume i zelene oaze) i komponente u okruženju (npr. drvenaste vrste i voda) značajno pridonose kvaliteti života na više načina (Chiesura, 2004.). U preglednom radu, Chiesura (2004.) navodi mnogobrojne pozitivne (zdravstvene, socijalne i ekonomske) učinke na stanovništvo $\mathrm{u}$ gradovima te manji broj negativnih učinaka uglavnom usmjerenih na osjećaje nesigurnosti stanovnika osobito ako se radi o neuređenim i nedovoljno osvjetljenim javnim zelenim površinama (tablica 1). U većem broju istraživanja (Conway, 2000.; Chiesura, 2004.) potvrđen je pozitivan utjecaj prirodnog zelenog okruženja na mentalno zdravlje i smanjen osjećaj stresa kod ispitanika kao i brži oporavak bolničkih pacijenata koji imaju 
Romana Caput-Jogunica i Lukrecija Martinis: Percepcija ukrasnog bilja studenata agronomije u Rekreacijski sportskom centru Jarun u Zagrebu

pogled s prozora sobe na zelene oaze, parkove i sl. u odnosu na pacijente s pogledom na zgrade. Mnogobrojni pozitivni učinci prirode na zdravlje i kvalitetu života čovjeka utvrđeni su u istraživanja Godbeya i sur. (1992.) prema kojem su boljeg zdravlja stanovnici koji veći dio slobodnog vremena provode $u$ prirodi.

Tablica 1. Pozitivni i negativni učinci urbanih parkova na stanovnike (Chiesura, 2004.)

Table 1 Positive and negative effects of urban parks on inhabitants (Chiesura, 2004)

\begin{tabular}{|l|l|}
\hline \multicolumn{1}{|c|}{$\begin{array}{c}\text { Pozitivni učinci } \\
\text { Positive effects }\end{array}$} & \multicolumn{1}{|c|}{$\begin{array}{c}\text { Negativni učinci } \\
\text { Negative effects }\end{array}$} \\
\hline $\begin{array}{l}\text { Zdravstveni učinci: smanjenje stresa, bolje } \\
\text { zdravlje i kvaliteta života, osjećaj relaksacije i } \\
\text { opuštanja }\end{array}$ & $\begin{array}{l}\text { Utvrđen veći osjećaj nesigurnosti osobito u } \\
\text { napuštenim i neuređenim prostorima, } \\
\text { vandalizam i strah od kriminala; } \\
\text { Socijalni učinci: socijalna integracija i } \\
\begin{array}{l}\text { Održavanje zelenih oaza utječe na budžet } \\
\text { interakcija između susjeda, smanjena } \\
\text { agresivnost i nasilničko ponašanje, poticanje } \\
\text { na uspostavljanje razgovora (,,social ties “) }\end{array}\end{array}$ \\
$\begin{array}{ll}\text { Ekonomski grada. } \\
\text { reducira zagađenost, pridonosi atraktivnosti } \\
\text { mjesta i većem interesu turista, otvaranje novih } \\
\text { radnih mjesta i većih prihoda, povećava } \\
\text { vrijednost na tržištu zemljišta i/ili nekretnina. }\end{array}$ & \\
\hline
\end{tabular}

U urbanim sredinama, stanovnici posjećuju parkove radi odmora i relaksacije. Za aktivno radno stanovništvo parkovi predstavljaju privremeni odmak od buke, užurbanosti, gužve na gradskim ulicama i svakodnevne rutine. Osim javnih parkova, u posljednje vrijeme u svrhu promicanja zdravstveno usmjerene tjelesne aktivnosti i zdravlja stanovnika u svim europskim gradovima posebna se pozornost usmjerava na uređenje sportsko rekreacijskih centara koji osim višeslojne funkcionalnosti odgovaraju na zdravstvene, sportsko rekreacijske, kulturne i estetske potrebe korisnika. Stvaranjem vizualno privlačnih prostora korisnicima se osigurava veći estetski doživljaj tijekom bavljenja sportom i rekreacijom (Wise, 2012.). Kulczyckia i sur. (2014.) analizirali su ulogu privlačnosti okoliša turistima koji tijekom odmora sudjeluju u sportsko rekreacijskim programima. Izbor destinacije turista koji žele aktivno provesti odmor ovisi o: ponudi sportskih programa, kvaliteti infrastrukture i njenom izgledu, te uređenosti i urednosti mjesta. 
Romana Caput-Jogunica i Lukrecija Martinis: Percepcija ukrasnog bilja studenata agronomije u Rekreacijski sportskom centru Jarun u Zagrebu

Urbano zelenilo u gradu Zagrebu može se podijeliti u nekoliko kategorija i sadržajnih formi: javni i privatni parkovi, školska igrališta i sportsko rekreacijski centri (Privora i sur. 2012.). U Zagrebu je nekoliko sportsko rekreacijskih centara: SRC Jarun, Bundek, Šalata, Svetice, Maksimirska naselja, Maksimir, Grana Klaka i dr. koji omogućuju građanima Zagreba, različite dobi, sudjelovanje u velikom broju sportsko rekreacijskih aktivnosti, koje se mogu grupirati na sportske igre i sportske igre na pijesku, aerobne fitnes programe (biciklizam, rolanje, trčanje, nordijsko hodanje, trim staze i dr.) te u parkovima gdje su vodene površine na sportove u vodi (veslanje, plivanje i dr.). Osim raznovrsne ponude sportskih aktivnosti za sve dobne skupine, u sportsko rekreacijskim parkovima važnu ulogu zbog mnogobrojnih pozitivnih učinaka ima uređen okoliš i raznovrsno ukrasno bilje. O percepciji ukrasnog bilja u gradovima i sportsko rekreacijskim centrima publiciran je mali broj istraživanja. Privora i sur. (2012.) proveli su istraživanje na uzorku 54 djece uključenih u školu tenisa u Teniskom centru Maksimir s ciljem utvrđivanja percepcije krajobraza oko teniskih igrališta i utvrđivanja interakcije teorijskih znanja o biljnim vrstama u nastavi i njihovom zapažanju biljnih vrsta u okolini. Utvrđeno je da $65 \%$ djece koja su sudjelovala u istraživanju redovito provodi slobodno vrijeme u prirodi sa svojim roditeljima i doživljavaju te boravke kao pozitivno iskustvo. $85 \%$ djece je pozitivno odgovorilo na pitanje: Primjećujete li zelenilo oko teniskih terena? Autori istraživanja u zaključku ističu važnost uređenih zelenih površina uz sportske terene i predlažu potrebu uvođenja atraktivnih izvannastavnih aktivnosti u škole koje će multidisciplinarno omogućavati djeci stjecanje teorijsko praktičnih znanja i boljeg snalaženja u prirodi. Židovec i sur. (2015.) ističu široku primjenjivost ukrasne hortikulture u obrazovanju i terapiji u radu s djecom, starijim osobama, bolničkim pacijentima, osobama $\mathrm{s}$ invaliditetom, žrtvama nasilja i svima ostalima zainteresiranima za rad s biljkama.

\section{CILJ ISTRAŽIVANJA}

Cilj ovog rada je utvrditi koje drvenaste vrste studenti Agronomskog fakulteta opažaju i prepoznaju tijekom sudjelovanja u aerobnim kondicijskim programima u sklopu nastave tjelesne i zdravstvene kulture na SRC Jarun. Osim navedenog, cilj rada je utvrditi potrebu unapređenja provedbe nastavnog procesa uvođenjem orijentacijskih karata koje sadrže drvenaste vrste uz postojeću sportsku infrastrukturu na Jarunu. 
Romana Caput-Jogunica i Lukrecija Martinis: Percepcija ukrasnog bilja studenata agronomije u Rekreacijski sportskom centru Jarun u Zagrebu

\section{METODE I MATERIJAL}

U svrhu provedbe istraživanja dizajniran je anonimni upitnik koji je sadržavao ukupno 10 pitanja: o davanju prednosti sudjelovanju u sportskim aktivnostima na otvorenim ili u sportskim objektima (1 pitanje), o prepoznavanju i uočavanju drvenastih vrsta na Jarunu (4 pitanja) te o prijedlozima studenata agronomije koje drvenaste vrste bi htjeli vidjeti na Jarunu (4 pitanja) i mišljenje vezano uz unapređenje aerobnih kondicijskih programa uvođenjem orijentacijskih karti s označenom pozicijom drvenastih ukrasnih vrsta (1 pitanje) uz raspoloživu sportsku infrastrukturu koje studenti moraju pronaći tijekom brzog hodanja, vožnje biciklom i/ili na rolama.

U istraživanju je sudjelovalo ukupno 70 studenata svih studijskih programa, od kojih je 63 ispunilo cijeli upitnik (44 studentice $(69,4 \%)$ i 19 studenata $(30,6 \%)$. Studenti su prethodno upoznati s ciljem istraživanja i zamoljeni da identificiraju potencijalno važne vrste u okolišu, koje su prema njihovom mišljenju prikladne za sportsko-rekreacijski centar.

\section{REZULTATI}

Analizom odgovora utvrđeno je da se studenti najbolje osjećaju kad se bave sportom na otvorenim sportskim terenima okruženi zelenilom (57 studenata, $90,48 \%)$. Drvenaste vrste na Jarunu prepoznaje 49 studenata $(77,78 \%)$. Učestalost opažanja drvenastih vrsti kod studenata varira od najviše 39 studenata $(61,90 \%)$ koji ih opažaju često do u manjem postotku studenata koji ih opažaju: stalno 8 (12,7\%); povremeno $14(22,22 \%)$ i studenata (2 studenta, $3,17 \%$ ) koji ne opažaju drvenaste vrste. Analizom pitanja s višestrukim odgovorima o prepoznavanju pojedinih drvenastih kultura, studenti su u najvećem broju naveli bor (Pinus sp., 33,33\%), zatim smreku (Picea, 23,81\%), vrbu (Salix sp., 17,46\%) i hrast (Quercus robur 12,70\%). Prema mišljenju većine ispitanika $(\mathrm{n}=43,68,25 \%)$ u pojedinim predjelima Rekreacijsko sportskog centra Jarun nedostaje drvenastih vrsti. Na pitanje koje drvenaste biljke bi trebale biti više zastupljene i zašto? - studenti su u najvećem postotku odgovorili: voćne vrste, magnolija, ukrasni grmovi i lipa. Kao razloge zašto su izabrali voćne vrste, naveli su izgled stabla i cvijeta i mogućnost degustacije plodova. Magnoliju su naveli radi lijepih cvjetova, dok su ostale biljne vrste rezultat osobnog izbora. 
Romana Caput-Jogunica i Lukrecija Martinis: Percepcija ukrasnog bilja studenata agronomije u Rekreacijski sportskom centru Jarun u Zagrebu

Drugi cilj ovog istraživanja je bio utvrditi interes studenata za unapređenje aerobnih kondicijskih programa izradom i primjenom orijentacijskih karti Jaruna s ucrtanim drvenastim biljkama. Većina studenata $(n=43,68,25 \%)$ je izrazila interes te su napravljene dvije orijentacijske karte: a/ za biciklističku stazu (slika 1.) i b/ za rolersku stazu (slika 2.), koju koriste rekreativci za brzo hodanje, trčanje i uz koju su smještene trim staze. Na orijentacijskim interaktivnim kartama obilježene su drvenaste vrste koje studenti tijekom aerobnih kondicijskih programa trebaju pronaći i prepoznati. Mape su koncipirane tako da je ispod obilježenog mjesta na kojimu se nalaze pojedine biljke, nalazi i njihova fotografija, snimljena na terenu, radi lakšeg prepoznavanja (slika 3).

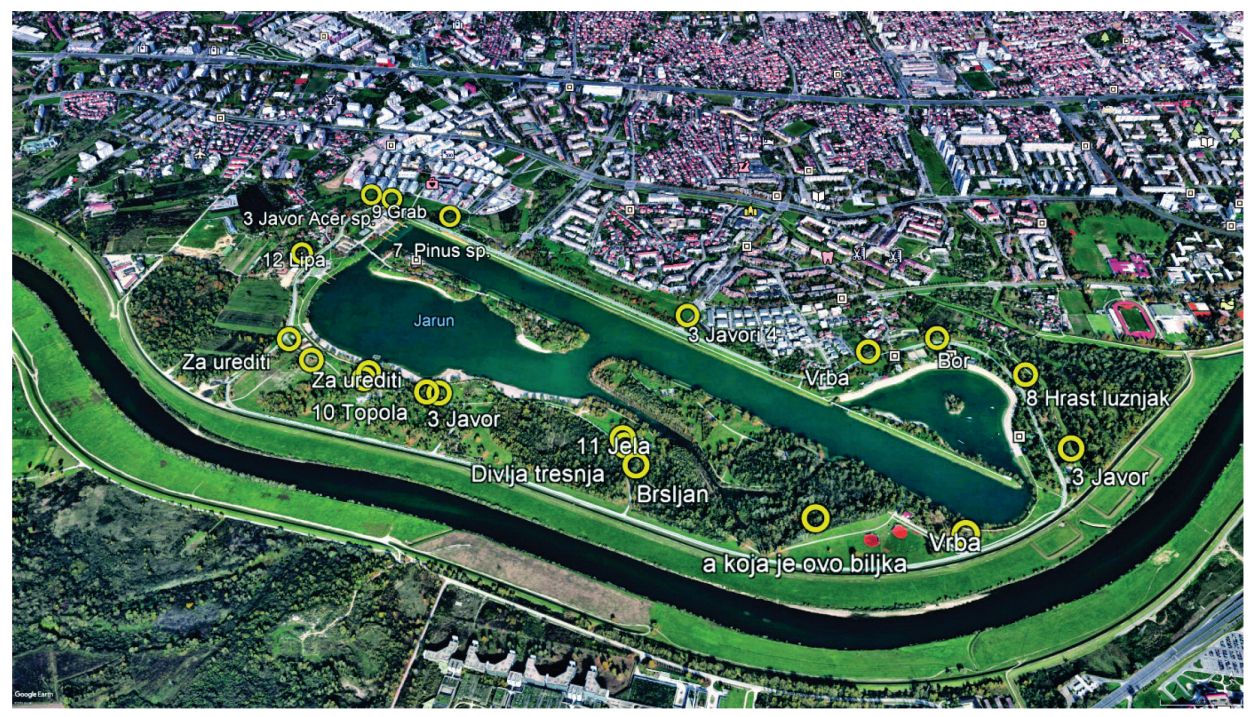

Slika 1. Orijentacijska karta s ucrtanim drvenastim biljkama uz biciklističku stazu na Jarunu (izrada Martinis, 2018.)

Figure 1 Orientation map with drawn woody plants along the bicycle path at Jarun (Martinis, 2018) 
Romana Caput-Jogunica i Lukrecija Martinis: Percepcija ukrasnog bilja studenata agronomije u Rekreacijski sportskom centru Jarun u Zagrebu

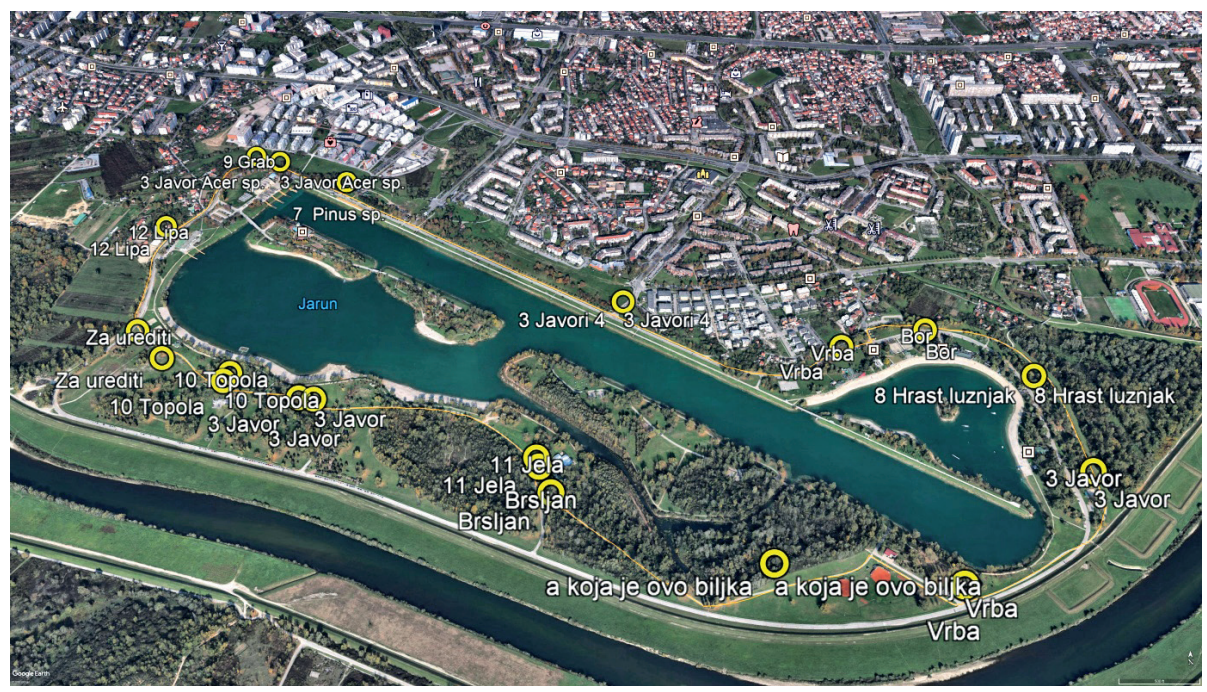

Slika 2. Orijentacijska karta s ucrtanim drvenastim biljkama uz rolersku stazu na Jarunu (Martinis, 2018.)

Figure 2 Orientation map with drawn woody plants along the roller skating path at Jarun (Martinis, 2018)

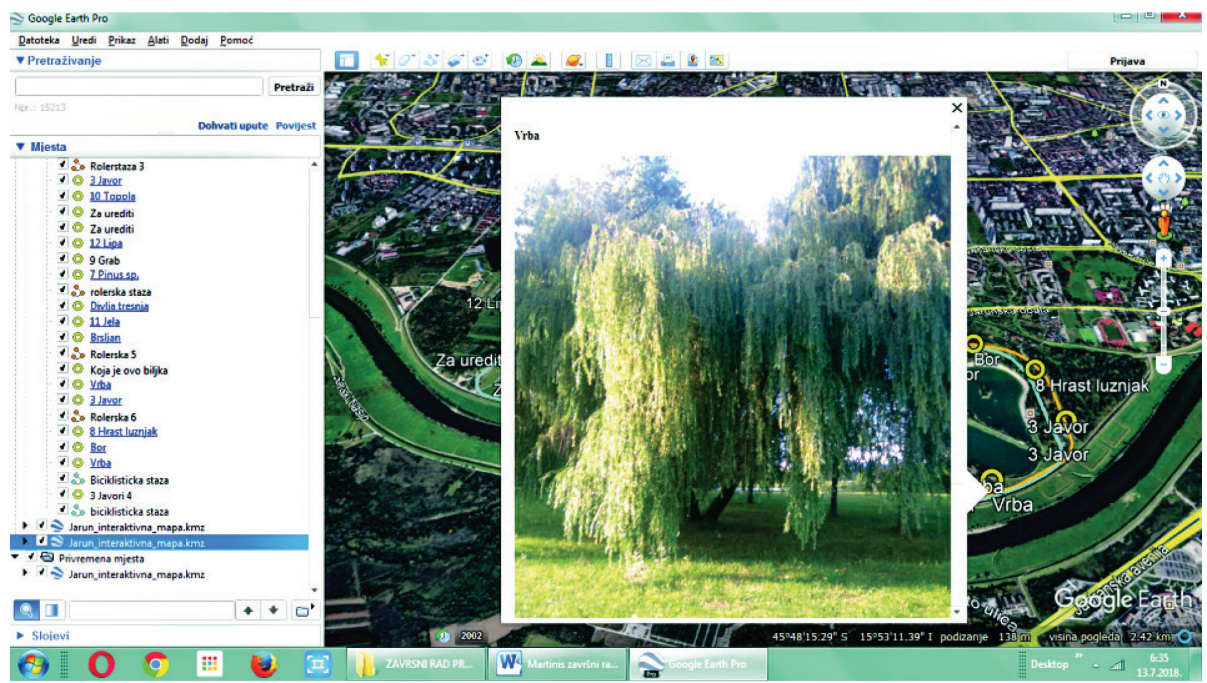

Slika 3. Primjer aplikacije interaktivne orijentacijske karte (izrada Martinis, 2018.)

Figure 3 Example of the application of an interactive orientation map (Martinis, 2018) 
Romana Caput-Jogunica i Lukrecija Martinis: Percepcija ukrasnog bilja studenata agronomije u Rekreacijski sportskom centru Jarun u Zagrebu

\section{ZAKLJUČAK}

Istraživanje provedeno na uzorku studenata s ciljem utvrđivanja percepcije ukrasnog bilja u Rekreacijsko sportskom centru Jarun predstavlja mali doprinos malobrojnim istraživanja u Hrvatskoj. U istraživanju je potvrđeno davanje prednosti sudjelovanju u sportsko rekreativnim programima u prirodi i kod studentske populacije. S obzirom da su u istraživanju sudjelovali studenti Agronomskog fakulteta, očekivano je potvrđeno opažanje i poznavanje biljnih vrsta tijekom sudjelovanja u aerobnim kondicijskim programima na Jarunu. Analizom mišljenja studenata, budućih magistara agronomije, utvrđen je nedostatak hortikulturnih nasada $\mathrm{u}$ pojedinim dijelovima Jaruna. Studenti predlažu da se posade voćne vrste, magnolija, lipa, te da se urede grmlja duž sportskih staza, a da se neuređeni prostori urede novom kombiniranom sadnjom drveća i ukrasnih grmova. Na osnovi rezultata ovog istraživanja u kojem je većina studenata potvrdila interes za izradom orijentacijskih karti s ucrtanim drvenastima biljkama izrađene su dvije verzije karata za dvije staze, koje se mogu koristiti u papirnatom i interaktivnom obliku.

\section{LITERATURA}

1. Chiesura, A. (2004.): The role of urban parks for the sustainable city. Landscape and urban planning. www.elsevier.com/locate/landurbanplan, (preuzeto 1. veljače 2019).

2. Conway, H. (2000.): Parks and people: the social functions: In: Woudstra. J. Fieldhouse, K. (Eds.) The Registration of Public Parks.

3. Godbey, G., Grafe, A., James, W., (1992.): The Benefits of Local Recreation and Park Services. A Nationwide Study of the Perceptions of the American Public. College of Health and Human development, Pennsylvania State University, Pennsylvania.

4. Kulczyckia K. and Halpennyb, E., A. (2014.): Sport cycling tourists' setting preferences, appraisals and attachments, Journal of Sport \& Tourism, 19:2, pp 169-197.

5. Privora, V. Grašo, K., Caput-Jogunica, R. i Han Dovedan, I. (2012.): Perception on Urban Greenery of Children Attending Tennis Schools in Zagreb, Agriculture Conspectus Scientificus. vol. 77: 2. pp 109-112.

6. Židovec, V., Skendrović Babojelić, M. i Šarić, D. (2015.): Osnove ukrasne hortikulture u obrazovanju i terapiji. Sveučilište u Zagrebu Agronomski fakultet. 
Romana Caput-Jogunica i Lukrecija Martinis: Percepcija ukrasnog bilja studenata agronomije u Rekreacijski sportskom centru Jarun u Zagrebu

7. Wise N. (2014.): Leyers of the Landscape: Representation and Perceptions of and Ordinary (Shared) Sports Landscape in a Haitian and Dominican Community. Geographical Research, 52(2): 212-222.

8. Alat za izradu interaktivne karte: Google Earth, Jarun_interaktivna_mapa.kmz

Adrese autora - Authors' addresses:

Izv. prof. dr. sc. Romana Caput-Jogunica

e-mail adresa: rcaput@agr.hr

Lukrecija Martinis, studentica diplomskog studija Hortikultura

e-mail adresa: lukrecija.martinis@gmail.com

Sveučilište u Zagrebu Agronomski fakultet

Katedra za tjelesnu i zdravstvenu kulturu

Svetošimunska cesta 25, 10000 Zagreb
Primljeno - received:

15.02.2019. 
Romana Caput-Jogunica i Lukrecija Martinis: Percepcija ukrasnog bilja studenata agronomije u Rekreacijski sportskom centru Jarun u Zagrebu 